\title{
STRESS E BURNOUT EM PROFESSORES DA EDUCAÇÃO ESPECIAL
}

\author{
Rosa Martins* \\ Ana Isabel Batista ${ }^{\dagger}$ \\ Sofia Campos $\ddagger$
}

\begin{abstract}
Resumo: As funções exigidas ao professor, no atual contexto social e profissional, requerem capacidades pessoais, que não se podem reduzir somente à acumulação de saberes. O ensino é considerado como uma profissão de alta pressão, muito exigente, sendo o burnout um síndrome muito comum. Os professores de alunos com necessidades educativas especiais estão sob uma sobrecarga psicológica ainda mais elevada, estando também mais sujeitos ao stress e ao burnout.

Assim, é nosso objetivo avaliar níveis de stress e burnout em professores de educação especial e verificar em que medida as variáveis sociodemográficas e psicossociais têm efeito significativo nesses níveis. Trata-se de um estudo quantitativo, transversal $e$ descritivo-correlacional. A amostra é constituída por 90 professores, ligados à educação especial da zona Centro do País. O instrumento de colheita de dados agrega questões de caracterização sociodemográfica, profissional e saúde, e ainda duas escalas: uma de avaliação dos níveis de stress e burnout (CPB-R, e outra para avaliação de auto-eficácia (SES). Para o tratamento estatístico foi utilizado o programa SPSS versão 19.

A amostra é maioritariamente feminina, casada, com licenciatura e uma média de idades de 46 anos. O stress está presente num elevado $n .^{\circ}$ de professores, sentindo estes falta de reconhecimento $e$ realização profissional. Paralelamente, a avaliação da supervisão, das condições organizacionais, o esgotamento emocional, o burnout global e a despersonalização ainda que referidas, apresentam níveis mais baixos. A auto-perceção é baixa a moderada para a maioria, com ênfase positivo para a eficácia perante as adversidades. O stress e o burnout são mais elevados nos professores com mais idade,
\end{abstract}

\footnotetext{
* Professora Coordenadora da Escola Superior de Saúde do Instituto Politécnico de Viseu. E-mail: rmartins.viseu@gmail.com

${ }^{\dagger}$ Professora da Educação Especial/Vereadora da Câmara Municipal da Guarda.

* Professora da Escola Superior de Saúde do Instituto Politécnico de Viseu.
} 
divorciados, a lecionar ao $3^{\circ}$ ciclo, com um horário semanal de 22/25 horas e com perceção de baixa eficácia.

As evidências, mostraram que o stress e burnout dos professores é diferenciado e multidimensional, contudo está presente num número muito significativo de professores de educação especial.

Palavras-chave: Professores, Educação Especial, Stress, Burnout, Auto-eficácia, Saúde.

\title{
Title: STRESS AND BURNOUT IN TEACHERS OF SPECIAL EDUCATION
}

\begin{abstract}
The functions required of the teacher, in the current social and professional context, require personal skills, which cannot only be reduced to the accumulation of knowledge. Teaching is considered a high-pressure job, very demanding with burnout being a very common syndrome. Teachers of students with special educational needs are at an even higher psychological burden and are also more prone to stress and burnout.

So it is our goal to assess stress levels and burnout in special education teachers and verify to what extent the sociodemographic and psychosocial variables have a significant effect on these levels. This is a quantitative study, cross-sectional and descriptivecorrelational. The sample consists of 90 teachers of special education in the country's central region. The data collection instrument aggregates questions of sociodemographic, professional, and health characterization, as well as two scales: one for assessment of stress levels and burnout $(C P B-R)$ and one for evaluating self-efficacy (SES). The statistical analysis was done using SPSS version 19.

The sample is mostly female, married, with a degree and an average age of 46 years. Stress is present in a high number of teachers, who feel the lack of recognition and professional achievement. Similarly, the evaluation of supervision, of the organizational conditions, emotional exhaustion, the total burnout, and the depersonalization, although referred have lower levels. Selfperception is low to moderate for most, with a positive emphasis on effectively to adversity. Stress and burnout is higher in older teachers, divorced, teaching the 3rd cycle, with a weekly schedule of 22/25 hours and with low efficacy perception.

The evidence showed that stress and burnout of teachers is differentiated and multidimensional, however it is present in a very significant number of special education teachers.
\end{abstract}

Keywords: Teachers, Special Education, Stress, Burnout, Self-efficacy, Health . 


\section{INTRODUÇÃO}

A Educação em Portugal tem sido alvo de constante debate, existindo consenso alargado quanto à necessidade de melhoria da sua a qualidade. Abrem-se, hoje, novos caminhos, exigem-se novas estratégias, novas conceções educativas, substancialmente, diferentes das que norteavam a intervenção do professor no passado. O corpo docente revela grande heterogeneidade, formação diversificada, defrontando-se com rápidas mudanças numa conjuntura que não corresponde às suas exigências, culturas e conceções. A população escolar é, também, cada vez mais heterogénea, com alunos provenientes de todos os meios sociais, culturais e económicos, o que tem como consequência que os seus interesses, motivações, aptidões e capacidades sejam diversificados.

O professor é o suporte fundamental e estruturador do percurso educativo e tem consciência das complexidades e das dificuldades que tem de enfrentar. As novas funções do professor, no atual contexto social e profissional, exigem muitas capacidades pessoais, que não se podem reduzir somente à acumulação de saberes. No exercício da sua atividade, o professor encontra-se sob pressão de vários fatores psicossociais, que são causadores de stress.

\section{STRESS E BURNOUT}

O stress produzido por atividades profissionais é designado por stress ocupacional, e é consequência do intenso ritmo de trabalho e alta exigência de concentração nas tarefas diárias. Podemos assim, afirmar que o stress ocupacional traduz o desajustamento existente entre as pessoas e o ambiente. No caso dos professores, o ambiente ocupacional e as exigências de competências resultantes do trabalho, são mediadas pela perceção de que, essas exigências, constituem uma ameaça à sua autoestima e ao seu bem-estar, provocando respostas e sentimentos negativos, geralmente acompanhados de mudanças fisiológicas e até bioquímicas ou patogênicas. $\mathrm{O}$ ensino é de facto considerado " uma profissão de alta pressão, muito exigente e em que o burnout comum," (Kuçuksuleymanoglu 2011, pp. 54).

O burnout é definido como uma combinação de sentimentos de exaustão emocional, despersonalização e um sentimento de falta de realização pessoal. A exaustão emocional implica a suposição de que o burnout é principalmente desenvolvido em trabalhadores cujas funções exigem altos níveis de envolvimento interpessoal. Já o sentimento de despersonalização corresponde a uma reação ao stress, que se expressa 
numa variedade de atitudes de pouco ou nenhum envolvimento nos problemas a quem têm de responder, tratando-os como objetos em vez de seres humanos (Kuçuksuleymanoglu, 2011). O sentimento de falta de realização pessoal é a falta de sentimentos de verdadeiro sucesso no trabalho, apesar dos seus esforços. Ela expressa-se em sintomas de stress, depressão e um sentimento de desprezo.

Face ao exposto, inferimos que os professores são um grupo de alto risco profissional, uma vez que estão mais propensos à baixa satisfação no trabalho, à baixa auto-eficácia e, consequentemente, ao aumento do stress e esgotamento.

Os estudos desenvolvidos por Pyalto, Pietarinen, Salmela-Acro, e Katariina (2011, pp.1101) mostram que embora a maioria dos professores considere o seu trabalho como uma actividade profissional gratificante, reconhecem também que constituem um grupo de sério risco de burnout, quando comparados com outros profissionais do meio académico. Devido às constantes mudanças, o professor possui cada vez menos tempo para executar o trabalho de ensinar, reduzindo assim oportunidades de trabalhos criativos. Como refere Sampaio (2009) há, cada vez mais, um distanciamento entre a execução (atividades realizadas pelos professores) e o planeamento das políticas que norteiam os seus trabalhos, a par de um universo de complexidade que envolve os resultados dessas tarefas. De entre as várias funções, atribuições e realidades, destacamos: tipo de instituições (pública ou privada), regime de trabalho (integral ou por turno), tipos de formação (pedagógica ou técnico), nível de formação (graduado, pós-graduado), contexto do aluno (faixa etária, classe social, nível do ensino, poder económico, etc..)

Apesar das diversas pesquisas realizadas sobre burnout em professores, com o objectivo de compreender com maior profundidade os níveis, dimensões e os fatores que contribuem para este síndrome, ainda pouco se sabe acerca da forma como o burnout se desenvolve. Compreender o desgaste profissional deste grupo torna-se emergente dado que o burnout em professores tem um impacto significativo, não apenas na motivação, saúde, trabalho e satisfação, mas também no comportamento e aprendizagem dos próprios alunos. Associado à insatisfação com o trabalho, o burnout tem ainda consequências afetivas e profissionais negativas (como depressão, e insuficiência no funcionamento ocupacional), não só para professores, mas também, para suas famílias, estudantes e escolas.

Sabemos que a intensidade do stress nos professores, relacionado com o trabalho varia de cultura para cultura e de país para país. No entanto, a maioria das pesquisas realizadas, na Europa e na América do Norte, têm 
mostrado altos níveis de stress ocupacional e/ ou desgaste entre grande número de professores. Há uma ampla evidência de que os professores, durante as suas carreiras, sofrem grande quantidade de stress que pode resultar em depressão, mau desempenho, atitude e alterações de humor e de personalidade, que por sua vez pode levar à doença e até aposentação prematura (Gomes, 2011).

Como salienta Sampaio (2009), o burnout nos tempos modernos, aparece em profissões cuja exigência cresce, mais e mais na mesma proporção em que as necessidades e exigências vão impossibilitando a realização das tarefas. A diferença entre o que o trabalhador oferece no trabalho, de empenho, dedicação e aquilo que ele recebe (reconhecimento de superiores e colegas, bons resultados nos desempenho dos alunos etc..) cria tensão, conflitos de incompatibilidade, geradores de burnout.

Existe consenso generalizado de que os professores com alunos com NEE, estão sujeitos a um maior grau de conflito e tensão. Um estudo de Cecil, Martin, Christopher, e William, (2012) demonstrou que a maioria dos professores de Educação Especial abandonam esta área, tomando lugares noutras áreas de Educação ou então recorrendo à aposentação. As razões apontadas para este abandono, prendem-se com o facto dos professores se sentirem desprezados, sobrecarregados pelas necessidades dos alunos, excesso de responsabilidades e sensação geral de menor poder. Uma combinação de condições de trabalho desagradáveis (sem apoio, pouco poder, despreparação...) e influências externas (falecimento de familiares, transferência de cônjuge, aposentação, divórcio, nascimento de filhos...) também contribuem para que esses professores abandonem este grupo.

Os pressupostos descritos levaram-nos a desenvolver esta investigação, que pretendia avaliar níveis de stress e burnout em professores de educação especial e verificar em que medida este construto é influenciado pelos factores sociodemográficos e psicossociais.

\section{METODOLOGIA}

A metodologia adotada num estudo consiste na descrição pormenorizada das ações implementadas para obter o resultado que se pretende. No nosso caso, pretendemos avaliar níveis de stress e burnout em professores de educação especial e verificar em que medida as variáveis sociodemográficas e psicossociais têm efeito significativo nesses níveis.

Trata-se de um estudo de caráter quantitativo, descritivo, transversal e correlacional. $\mathrm{O}$ método de amostragem escolhido foi $\mathrm{o}$ não- 
probabilístico, por conveniência, resultando uma amostra que é constituída por 90 professores, a lecionar em Escolas Públicas, com alunos com Necessidades Educativas Especiais.

$\mathrm{O}$ instrumento de colheita de dados utilizado, integra um questionário com questões de caracterização sociodemográfica, profissional e saúde, uma escala de avaliação dos níveis de stress e burnout em docentes de CPB-R (Moreno-Jiménez, B., Hernández, E. G. \& Gutiérrez, J. L. G, 2000, traduzidas por Patrão \& Santos Rita, 2009) e a escala de avaliação de auto-eficácia SES traduzida para a população portuguesa por PaisRibeiro, (1995), ambas aplicados por autopreenchimento.

A colheita de dados decorreu entre Abril, Maio e Junho de 2012, nas Escolas e Agrupamentos de Escolas do Distrito da Guarda, sendo que, os questionários foram entregues pessoalmente, solicitando-se $\mathrm{o}$ seu autopreenchimento, e garantindo-se a confidencialidade neste processo.

\section{APRESENTAÇÃO DOS RESULTADOS E SUA ANÁLISE}

A amostra deste estudo é constituída por 90 professores a desenvolver a sua atividade profissional em vários ciclos de estudos. Os dados sociodemográficos caracterizadores da amostra, revelam desigualdade na repartição por género já que 66 pertencem ao género feminino e 24 ao género masculino. Estes resultados não nos surpreendem uma vez que em Portugal (de acordo com os dados do INE, 2011) se "evidencia um corpo profissional essencialmente constituído por mulheres, embora com algumas variações entre os diferentes níveis e entre a natureza institucional que caracteriza a oferta. Os valores mais elevados do índice são encontrados na educação pré-escolar, sempre acima de 95\%, embora em diminuição ao longo do tempo. Os valores mais baixos são os dos docentes do ensino secundário e $2 .^{\circ}$ e $3 .^{\circ}$ ciclos do básico, com uma tendência inicial para subida e posterior estabilização (em redor dos $70 \%$ no público) na década de 90 ".

A idade em média é de 46,44 anos, sendo os elementos do sexo feminino $(M=44,73)$ ligeiramente inferior à do sexo masculino $(M=$ 51,17). Estes dados estão também de acordo com as estatísticas nacionais ao referirem "que considerando a idade dos professores, a tendência é para o envelhecimento progressivo do corpo docente, situação menos evidente sobretudo nos docentes do ensino básico (1..$^{\circ}$ ciclo) (INE, 2009).Os resultados relativos ao estado civil permitem-nos verificar que, a maioria $(66,7 \%)$ dos professores são casados, seguindo-se os solteiros $(17,8 \%)$ - todos do sexo feminino, - e os divorciados $(15,6 \%)$. São vários os estudos que demonstram que o estado civil exerce influência no 
desempenho profissional dos indivíduos: destacamos a pesquisa de Chaves (2008), cujas conclusões demonstraram que o casamento é um bom preditor de bem-estar subjetivo. A evidência desse resultado pode estar ainda refletido no apoio social que o casamento possibilita aos professores, tendo em vista o contexto de sobrecarga de atividades a que se dedicam.

Os professores inquiridos, na sua maioria, $(82,2 \%)$ possuem uma licenciatura; seguindo-se $(11,1 \%)$ com mestrado e em $3^{\text {a }}$ posição o bacharelato em $(6,7 \%)$. De notar que nenhum professor referiu possuir doutoramento.

Como podemos verificar, não existem grandes diferenças na habilitação em função do género, em virtude de se manterem valores percentuais equivalentes nos vários níveis de formação académica. Deste modo a licenciatura continua a ser a habilitação prevalente, para homens e mulheres, contudo nenhum dos homens da nossa amostra possui o grau de mestre em contraste com $11,1 \%$ das mulheres.

$\mathrm{Na}$ verdade a evolução verificada no sistema educativo fez-se acompanhar pela qualificação sustentada ao longo do período em análise da generalidade dos docentes. Diz-nos o relatório de actividades anuais do Ministério da Educação (ME), que em 2012,cerca de 94\% dos docentes do ensino secundário e do $3 .^{\circ}$ ciclo do ensino básico possuíam no mínimo uma licenciatura, percentagem que assumia o valor de $83 \%$ na educação pré-escolar.

A formação especializada dos professores está restrita apenas a um pequeno número, uma vez que apenas $24,4 \%$ afirma possui-la, contrariamente à maioria $(75,6 \%)$ que não tem. A análise dos resultados por sexo mostra, que a formação especializada está apenas presente na amostra feminina, uma vez que nenhum dos homens assinalou esta opção.

Sabemos que a inclusão de alunos com necessidades educativas especiais é um processo recente que implica que os professores conheçam técnicas e instrumentos de observação e avaliação que permitam uma intervenção educativa adequada. Corroboramos da opinião de Nauege (2011) quando afirma que todas as escolas devem ter uma especial preocupação com a formação do seu pessoal mediante os objectivos que define. No caso da inclusão de alunos com Necessidades Educativas Especiais, essa formação torna-se obrigatória para lhes ser prestada uma educação adequada. Pelo menos os educadores, e os professores precisam fazer formação específica para perceberem a problemática dos seus alunos, a forma como atuar no sentido de elaborar estratégias e qual o papel das novas tecnologias na educação. Contudo, a realidade de Escola que temos nem sempre demonstra estar preparada para estas mudanças. 
Veja-se o estudo "A Educação Especial na Última Década - Evolução e Tendências" levado a cabo pelo Núcleo de Orientação Educativa e de Educação Especial (1993), que referindo-se ao número de docentes especializados, afectos às equipas de Educação Especial em 1987 era de $32 \%$, enquanto que em 1992 a percentagem descia para 28\%. Dos 2519 docentes afectos às Equipas de Educação Especial, em 1992, 1814 não eram especializados e apenas 705 possuíam uma especialização; acrescentam que a maioria dos docentes especializados se encontrava na região de Lisboa, e as regiões do Alentejo e Algarve eram as que apresentavam menor número de docentes especializados.

Ao considerarmos o tempo total de serviço docente dos nossos professores, constatamos que o grupo com maior representatividade percentual $(35,6 \%)$ se encontra no primeiro escalão [7-17 anos];seguindose o segundo [18-26 anos] para 33,3\%, e 31,1\% integra o grupo dos 2738 anos. Existem posicionamentos inversos entre homens e mulheres, uma vez que as mulheres mantém a distribuição da amostra total e os homens recaem em primeiro lugar no escalão (27-38 anos) seguindo-se o segundo (18-26 anos) e só em terceiro lugar os do primeiro escalão (7-17 anos), ou seja, os indivíduos do sexo masculino têm mais anos de experiencia profissional na função docente que as mulheres o que não nos surpreendeu tendo em conta as médias de idade apresentadas e anteriormente analisadas.

Como esperávamos a grande maioria $(97,8 \%)$ dos professores desenvolve a sua actividade profissional em escolas públicas e apenas $2,2 \%$ em escolas privadas. Constatamos ainda, que os homens leccionam exclusivamente em escolas públicas e apenas 2,2\% das mulheres em privadas. Como refere Gouveia (2010), a situação dos professores não se verifica de igual modo entre a oferta privada e a oferta pública. Veja-se por exemplo que nos anos mais recentes os estabelecimentos privados apresentam sempre uma relação alunos/docente superior, embora no ensino secundário e básico (2..$^{\circ}$ e $3 .^{\circ}$ ciclos) tal só se verifique a partir do ano letivo 1995/96. Por outro lado, é sobretudo no ensino público que se observa uma redução sustentada do indicador alunos por docente.

O nível de ensino exercido por $35,6 \%$ dos professores é o $1^{\circ}$ ciclo, seguindo-se o $3^{\circ}$ ciclo e o secundário com igual valor percentual $(22,2 \%)$ e na última posição temos o $2^{\circ}$ ciclo para $20,0 \%$ dos professores. Estes dados estão enquadrados nas normativas estabelecidas pela Lei de Bases do Sistema Educativo Nacional. De facto, como nos diz Alarcão (2011), há aspectos comuns à atividade de qualquer professor, seja qual for o respetivo nível de ensino; mas há também aspectos específicos que devem ter em conta os objetivos de cada nível e as particularidades da faixa 
etária da população escolar que esse professor é chamado a lecionar.

Quisemos ainda identificar $o n^{o}$ de alunos com NEE a cargo do professor: os resultados demonstram que para o total da amostra $(28,9 \%)$ tem 3-4 alunos, seguindo-se $26,7 \%$ com $1-2$, na terceira posição $24,4 \%$ com 5-6, e os restantes 20,0\% refere mais de 6 alunos. A legislação Portuguesa, através do Despacho n. ${ }^{\circ}$ 14026/2007, de 3 de Julho, com a redacção dada pelo Despacho n. ${ }^{\circ} 13170 / 2009$, de 4 de Junho, refere, no n. ${ }^{\circ}$ 5.4, que "As turmas que integrem crianças e jovens com necessidades educativas especiais de carácter permanente, e cujo programa educativo individual assim o determine, são constituídas por 20 alunos, no máximo, não podendo incluir mais de 2 alunos nestas condições." Torna-se, assim, condição no programa educativo individual a necessidade do aluno integrar uma turma reduzida. A partir deste pressuposto, a turma só pode integrar o máximo de vinte alunos, podendo, naturalmente, ser constituída por um número menor. Acresce que, para além disto, só pode incluir o máximo de dois alunos com necessidades educativas especiais, de carácter permanente. Esta medida aplica-se aos vários ciclos como comprovamos pelo Decreto-Lei n. $.^{\circ} 3 / 2008$, de 7 de Janeiro, que refere, no seu artigo $1^{\circ}$, que se aplica à educação pré-escolar e aos ensinos básico e secundário dos sectores público, particular e cooperativo.

Um outro dado que quisemos identificar foi $\mathrm{o} \mathrm{n}^{\mathrm{o}}$ de horas semanais leccionadas pelos Professores: os resultados demonstram que 42,2\% lecciona $22 \mathrm{~h}$ semanais, seguindo-se com o mesmo valor percentual $(28,9 \%)$ os que referem ter menos ou igual a $20 \mathrm{~h}$ e $25 \mathrm{~h}$ semanais. A análise em função do género, mostra que também nesta variável existem diferenças entre homens e mulheres, uma vez que estas se distribuem primariamente pelas $22 \mathrm{~h}$, seguindo-se $25 \mathrm{~h}$ e só por fim menos ou igual a $20 \mathrm{~h}$ semanais. No caso dos homens verificamos que tem um $\mathrm{n}^{\circ}$ mais reduzido na carga horária uma vez que $13,3 \%$ refere um $\mathrm{n}^{\circ}$ menor ou igual a $20 \mathrm{~h}$, seguindo-se com igual valor percentual $(6,8 \%)$ os que assinalam as opções $22 \mathrm{~h}$ e $25 \mathrm{~h}$. Estes resultados estão em nossa opinião relacionados com a diferença de idades encontradas entre os professores do sexo masculino e feminino que anteriormente explicámos, mas também com a legislação vigente: o Decreto-Lei n. ${ }^{\circ}$ 15/07, de 19 de Janeiro, que aprovou a nova versão do Estatuto da Carreira docente, prevê que o pessoal docente dos $2 .^{\circ}$ e $3 .^{\circ}$ ciclos do Ensino Básico e os do Ensino Secundário e de Educação Especial tem direito a uma redução na sua componente lectiva até ao limite de 8 horas quando reunidos os seguintes requisitos: "De duas horas logo que os docentes atinjam 50 anos de idade e 15 anos de serviço docente; De mais de duas horas logo que os docentes atinjam 55 anos de idade e 20 anos de serviço docente; 
De mais quatro horas logo que os docentes atinjam 60 anos de idade e 25 anos de serviço docente".

A situação profissional, da maioria dos nossos participantes é bastante estável, uma vez que $75,6 \%$ são professores que estão no quadro de nomeação definitiva (QND) 13,3\% integram o quadro de nomeação provisória (QNP), e apenas 11,1\% está em regime de Contratação. Também estes dados estão de acordo com a legislação de índole laboral que tem vigorado em Portugal, e das novas atualizações, não podendo nós dissociar a idade dos docentes e a alargada experiencia profissional da maioria da amostra.

Um dado que nos pareceu relevante conhecer em função dos objetivos do no nosso estudo, prende-se com a ocorrência nos últimos 6 meses de algum acontecimento negativo: os resultados permitem-nos verificar que, a maioria $(82,2 \%)$ dos professores, responde negativamente, contudo $17,8 \%$ (todos elementos do sexo feminino) responde afirmativamente. De acordo com Miranda (2008), todas as pessoas têm um potencial que é seu, constituído e desenvolvido nas suas relações com o mundo. Todos nós, temos sempre um relato retirado das vivências de sala de aula, dos relacionamentos afectivos, do seio familiar e do meio social em que vivemos que podem resultar em sentimentos negativos. Todas estas dificuldades, na opinião de Nóvoa (2002), são agravadas nos professores pelo facto de viverem momentos de grande instabilidade profissional, conviverem com tensões ao lidarem com realidades locais e situações escolares marcadas por fenómenos de exclusão, de agressividade e de conflito social. Consideramos que o conjunto dos fatores descritos é potencializado no feminino, uma vez que acresce a tudo isto as tarefas domésticas e assistência familiar que continuam a ser responsabilidades essencialmente atribuídas às mulheres. Os resultados sobre a questão "esteve de baixa médica" permitem-nos verificar que, à semelhança da anterior a maioria $(88,9 \%)$ dos professores, responde "não", seguindo-se $(11,1 \%)$ que respondem afirmativamente. A análise por sexo, mostra que ambos os grupos se posicionam maioritariamente na alternativa não, contudo na opção "sim" apenas se posicionam $2,2 \%$ dos homens contra $8,9 \%$ das mulheres. Os relatos da pesquisa de Gasparini, Barreto e Assunção (2006) esclarecem que, os elementos que podem estar associados às queixas, às doenças e às baixas do professor, não se restringem ao exercício de sua função dentro da sala de aula, mas sim da singularidade percetiva e das influências ambientais. Quando o professor ministra aulas em várias turmas para alunos em níveis de ensino, escolas e tempos lectivos diferentes, a preparação das aulas vai requerer avaliações múltiplas e esquemas variados para cada sala. Será necessário 
maior investimento de tempo para elaboração e execução das atividades, bem como, dedicação e esforço intelectual, além do investimento emocional, na medida em que diariamente são estabelecidos vínculos emocionais com alunos, e colegas de trabalho.

Em estreita ligação com a questão anterior, quisemos ainda saber se os professores sofriam de doenças crónicas: como era de esperar na sequência das respostas anteriores, a maioria (93,3\%) responde negativamente, não obstante, $6,7 \%$ assume possuir doença crónica, sendo todos os respondentes do sexo feminino. Estes resultados não nos surpreenderam, pois sabemos que as transformações sociais, as reformas educacionais e os modelos pedagógicos derivados das condições de trabalho dos professores, provocaram mudanças profundas na profissão docente com implicações na vida familiar na sua saúde e no absentismo. Em contrapartida, como referem Esteves, Jacobs, e Ruiz Fernández (2009), embora as mudanças excessivas num curto período de tempo possam provocar problemas de saúde aos professores, os resultados desta pesquisa reflectem exatamente um efeito contrário. Isto é, essas mudanças do contexto da vida docente podem estar a influenciar positivamente o seu bem-estar, na medida em que percebem que estão a fazer um investimento em si próprios na aquisição de formação superior, reflectindo-se assim na imagem do profissional e da sociedade como um todo. Isso reforça o sentimento de satisfação e valorização do seu trabalho. Não obstante ao que fica dito, investigações levadas a cabo por Gasparini, Barreto e Assunção (2006) sobre as condições de saúde e trabalho de professores, destaca uma grande proporção de adoecimento numa população relativamente jovem, com queixas importantes relacionadas principalmente com o funcionamento psíquico, como cansaço mental e nervosismo. Um outro estudo liderado por Naujorks, (2008), investigou o stress e os seus principais agentes desencadeadores, frente à inclusão de alunos com necessidades educacionais especiais onde foram identificados vários agentes stressores com os quais o professor tem de lidar no seu cotidiano profissional. A falta de preparação dos professores para o processo de inclusão foi a principal fonte geradora de stress por eles apresentada. Acrescentam como fatores de agravamento do problema, a quase inexistência de projetos de educação continuada que os capacite para enfrentar a "nova" exigência educacional; o elevado número de alunos por turmas; as infra-estruturas físicas inadequadas; a falta de trabalhos pedagógicos em equipa; o desinteresse da família em acompanhar a trajetória escolar de seus filhos; a indisciplina cada vez maior; a desvalorização profissional e os baixos salários, situações que fogem de seu controlo e preparação. Sentimentos de desilusão, de 
desencantamento com a profissão foram frequentemente relatados, evidenciando a vulnerabilidade dos profissionais estudados ao stress. A autora desse estudo conclui que as atividades pedagógicas permeadas por circunstâncias desfavoráveis forçam a uma reorganização e improvisação no trabalho planeado, distorcem o conteúdo das atividades e tornam o trabalho descaracterizado em relação às expectativas, gerando um processo de permanente insatisfação e induzindo a sentimentos de indignidade, fracasso, impotência, culpa e desejo de desistir, entre outros.

Os resultados conseguidos pela aplicação do CPB-R, que avalia níveis de stress e burnout, neste grupo de participantes, mostram maioritariamente o seguinte: $80 \%$ dos professores sofre de stress de papel, ou seja o stress que é produzido pelas funções que estão relacionadas com a sua profissão; $60 \%$ sente falta de realização profissional, o que traduz sentimentos de incompetência e de baixa produtividade no trabalho, bem como de descontentamento a nível pessoal; $55,6 \%$ revela preocupações profissionais evidenciadas no trabalho, nomeadamente a falta de segurança e de continuidade no próprio trabalho, entre outras preocupações; $64,4 \%$ manifesta sentimentos de falta de reconhecimento ao nível do seu trabalho que segundo (Jiménez, González e Gutiérrez, (2000) se deve na maioria dos casos aos salários baixos, à escassez de serviços de apoio para problemas profissionais, entre outros...

Os resultados mostram ainda que $35,6 \%$ dos inquiridos sofre de burnout, entendido como uma resposta ao stress laboral crónico, que conduz ao aparecimento de condutas negativas relativamente aos clientes e ao trabalho, levando ao aparecimento de problemas de ordem prática e emocional tanto para o trabalhador como para a organização na qual exerce as suas funções; $48,9 \%$ apresenta esgotamento emocional que se caracteriza pela sensação de exaustão emocional e física, na qual o sujeito constata que não possui energias suficientes para continuar a trabalhar; surge então o distanciamento do professor em relação ao aluno, o endurecimento afetivo e falta de empatia; $2,2 \%$ em despersonalização, dimensão do contexto interpessoal do burnout que se refere a atitudes de distanciamento emocional direccionadas às pessoas a quem o sujeito deve prestar serviços, bem como aos colegas de trabalho; $43,8 \%$ queixam-se da supervisão, ou seja, avaliam de forma menos positiva o estilo da direção o apoio em relação ao supervisor; $46,7 \%$ referem falta de condições organizacionais nomeadamente as condições nas quais se realiza o seu trabalho: materiais e recursos disponíveis.

Globalmente estes resultados estão em convergência com muitos outros já publicados, apesar dos índices de stress de papel no nosso caso 
serem bastante elevados. Temos consciência que o stress é um problema dos tempos modernos, que embora possa ser entendido como benigno, (assim entendido provavelmente por $20 \%$ dos nossos professores), também pode fazer muito mal a saúde, dependendo de como cada sujeito lida com as diferentes situações. O processo de stress é um conceito que não encontrou ainda uma definição clara, objetiva, consensual e definitiva. No entanto na opinião de Polónio, (2011, p. 75), "há actualmente uma pressão exercida especialmente pelas novas tecnologias necessitando uma adaptação sem um preparo prévio. Isso favorece a tensão, a insatisfação e a ansiedade, o que esgota o professor".

$\mathrm{Na}$ mesma linha, Benevides-Pereira (2002), conclui de um estudo sobre professores que há efetivamente uma diminuição da qualidade de vida dos profissionais, afetados por um stress recente $\mathrm{e}$ consequentemente, uma deterioração na qualidade de vida pessoal, afetando diretamente as relações interpessoais tanto na esfera pública como íntima, com prejuízos emocionais. Também Nauege (2011), infere das suas pesquisas que o trabalho do professor é stressante, porque muitas vezes numa hora ele deve tomar muitas decisões e enfrentar diversas "situações educativas conflitivas" (p.18) acresce a tudo isto, o facto de muitos não conseguirem deixar de pensar no trabalho pós-expediente. $\mathrm{O}$ distanciamento existente entre o plano e a ação pedagógica, devido às situações de imprevisto e variáveis incontroláveis, é em sua opinião, o constante gerador de preocupações, falta de realização e de reconhecimento profissional.

É hoje inegável que as profissões onde é necessário o contacto com outras pessoas são aquelas em que o risco do aparecimento do burnout é mais elevado, como é o caso da profissão docente. A severidade de burnout entre os profissionais de ensino já é, atualmente, considerada por alguns autores como superior à dos profissionais de saúde, colocando-a como uma das profissões de alto risco (Farber, 1991; Gouveia 2010). A profissão docente, na qual é inevitável o contacto permanente com terceiros, revela-se para muitos como um constante desafio. No entanto, pode igualmente desencadear medos e ameaças tanto no campo profissional como no campo pessoal (Capelo, Pocinho \& Santos, 2013). $\mathrm{O}$ professor encontra-se numa situação de trabalho que sente que não consegue suportar, mas ao mesmo tempo também não pode desistir. Atualmente, o papel docente não é somente o de transmitir conhecimentos aos alunos, pois para além de ensinar, o professor deve participar ao nível do planeamento das actividades escolares, o que implica uma maior dedicação por parte destes profissionais sobretudo no caso dos alunos com necessidades educativas especiais, estendendo-se 
esta também às famílias e à comunidade (Gasparini, Barreto \& Assunção, 2006). A autoeficácia faz parte dos fatores que constituem os mecanismos psicológicos que influenciam o comportamento das pessoas diante de uma tomada de decisão para realizar uma ação. A importância das crenças de auto-eficácia tem sido corroborada por diversas evidências empíricas, pois influenciam em grande parte a vida dos professores, ou seja, espelham o quanto eles se motivam e persistem perante obstáculos, avaliam a sua vulnerabilidade ao stress, à depressão e às escolhas por si feitas (Bastos, 2008). Na busca desta informação podemos constatar, que em termos de auto eficácia global dos professores inquiridos, os valores oscilaram entre 36 (Min.) e 73 (Max.) com uma média de 58,31 e um desvio padrão de10,11. Em termos classificativos 33,3\% dos nossos professores apresenta auto eficácia elevada, 28,9\% moderada e 37,8\% auto eficácia baixa. Diz Nauege, (2011) que quando as crenças individuais de auto-eficácia forem baixas no conjunto de professores de uma unidade escolar, o primeiro impacto negativo ocorrerá com o nível de metas académicas a serem estabelecidas. Uma auto-avaliação otimista da própria capacidade, pode ser muito vantajosa, desde que não seja muito distorcida. Dizem-nos ainda os mesmos autores, que em certos casos uma avaliação verdadeira de sua capacidade pode limitar a pessoa. Por exemplo, quando pessoas errarem no seu autojulgamento, por valorizarem demais suas capacidades de ensinar, teriam mais resistência para mudar seus métodos e melhorar. Portanto, é melhor que tenham dúvidas, pois isso abre espaço para busca e aperfeiçoamento.

Os resultados da nossa investigação demonstram estes diferentes olhares sobre si próprios, e parecem ser coerentes com os índices de stress e burnout encontrados, uma vez que, como refere Mota (2010), os factores somáticos e emocionais também influenciam a perceção de autoeficácia. Situações como a ansiedade, o stress, a excitação e certos tipos de humor levam o indivíduo a não se sentir capaz de enfrentar determinadas tarefas. No momento em que as pessoas têm pensamentos negativos e temores sobre suas capacidades e reações, ocorre a sinalização induzindo-as a julgamento de que poucos são capazes frente à situação apresentada. A promoção de bem-estar emocional e redução de estados emocionais negativos é um meio que se tem para aumentar as crenças de auto-eficácia, pois tem-se a capacidade de modificar os próprios pensamentos e sentimentos, e, por outro lado, as crenças de auto-eficácia podem ter influência poderosa nos próprios estados psicológicos dos indivíduos. 


\section{CONCLUSÕES}

O estudo do stress e burnout em professores deverá ser entendido como uma experiência individual, específica e variável nos contextos de trabalho. Apesar das múltiplas definições de burnout encontradas existem vários elementos comuns em todas elas: a predominância de sintomas relacionados com a exaustão mental e emocional, a sensação de fadiga e/ou depressão; a ênfase nos sintomas comportamentais e mentais para além dos sintomas de natureza física; a relação destes sintomas com o trabalho; manifestações sintomáticas diversas, na ausência de antecedentes psicopatológicos com implicações no absentismo; a diminuição de eficácia e desempenho no trabalho, devida a atitudes e comportamentos negativos.

O stress é considerado um dos indicadores do mal-estar docente, pois em Portugal verificou-se que um em cada três professores, sente que a sua profissão é stressante e um em cada seis se encontra em estado de exaustão emocional, dados estes que saem reforçados com o produto da nossa investigação.

Apesar dos avanços significativos que se vão notando, sentimos que os estudos e pesquisas científicas sobre o stress e o burnout em professores, a desempenhar funções no interior do país, carecem de um referencial que permita avaliar globalmente os fundamentos teóricos de ordem filosófica, sociológica, biológica e psicológica - em suma, a vida em toda a sua extensão.

Relançar um olhar sobre o percurso desta investigação e desenvolver uma síntese final é o desafio que neste momento se nos coloca. Assim alicerçados nos objetivos inicialmente definidos neste processo investigativo e considerando-os eixos orientadores desta pesquisa subtraímos as seguintes conclusões:

$\checkmark$ O perfil sociodemográfico da amostra do nosso estudo caracterizase por ser maioritariamente feminina, possuir uma média de idade de 46,44 anos, com estado civil de casado e com dois filhos em média.

$\checkmark$ Já o perfil profissional caracteriza-se por ter como principal habilitação académica a licenciatura, sem especialização, com um tempo de serviço que oscila entre 7 e 26 anos e a lecionar maioritariamente em escolas públicas com vinculo QND. O ensino que ministram corresponde ao $1^{\circ}$ e $3^{\circ}$ ciclos, apoiam em média 3 a 4 alunos com necessidades educativas especiais e praticam um horário semanal de 22 horas.

$\checkmark$ O perfil de saúde insere-se num padrão saudável, uma vez que a grande maioria não vivenciou acontecimentos negativos, não esteve de baixa médica e não possui doenças crónicas. 
$\checkmark$ A sobrecarga profissional encontrada caracteriza-se por um $n^{\circ}$ elevado de professores em stress de papel, com sentimentos de falta de reconhecimento e realização e ainda, com muitas preocupações profissionais. Paralelamente, a avaliação da supervisão, das condições organizacionais, o esgotamento emocional, o burnout global e a despersonalização ainda que referidas são dimensões com níveis mais baixos.

$\checkmark$ A auto-perceção que os professores demonstram sobre a sua eficácia global oscila entre o baixo e o moderado para a maioria, com ênfase positivo para a eficácia perante as adversidades.

$\checkmark$ As correlações estabelecidas entre variáveis, confirmam que o stress e burnout dos participantes no estudo é mais acentuado: nos indivíduos com mais idade, divorciados, com tempo de serviço entre 18 e 26 anos, a leccionar ao $3^{\circ}$ ciclo, com um horário semanal de 22/25 horas, que vivenciaram nos últimos tempos acontecimentos negativos e com perceção de baixa eficácia.

$\checkmark$ De modo inverso, o género, o $\mathrm{n}^{\circ}$ de filhos, as habilitações académicas, os cursos de especialização, a situação (vinculo) profissional e $o \mathrm{n}^{\circ}$ de alunos com necessidades educativas especiais, mostraram não exercer influencia no stress e burnout destes professores.

Assim, considerando algumas das condições, decorrentes da análise realizada e das conclusões apresentadas, queremos deixar algumas sugestões que integrem um quadro de ações que privilegiem:

-Programação de atividades letivas atempadas;

-Maior desenvolvimento de competências pessoais e pedagógico/ didáticas, sobretudo no complexo processo de inclusão de alunos com necessidades educativas especiais na escola do ensino regular;

-Ajustar Legislação à realidade presente;

-Maior sensibilização e vigilância da saúde ocupacional (física e psicológica);

Acreditamos, que só identificando e compreendendo os desafios enfrentados pelos professores de alunos com necessidades educativas especiais, poderemos propor intervenções centradas na aceitação e valores que visem promover a flexibilidade psicológica, a capacidade de viver cada momento, em suma, maximizar a Qualidade de Vida dos Professores. 


\section{FONTES E BIBLIOGRAFIA}

Alarcão, I. (2011). A constituição da área disciplinar de didáctica das línguas em Portugal. Linguarum Arena, 1(1), 61-79.

Bastos, C. (2008). Inteligência emocional, liderança e desempenho: Qual a relação? Um caso na administração pública local (Dissertação de mestrado não publicada). Instituto Superior de Psicologia Aplicada, Lisboa.

Benevides-Pereira, A. M. T. (2002). Burnout: Quando o trabalho ameaça o bem-estar do trabalhador. São Paulo: Casa do Psicólogo.

Capelo, M. R., Pocinho, M., \& Santos, C. (2013). Stresse e coping em educadoras de infância portuguesas: Um estudo exploratório, Trabajo, 28, 69 - 81.

Chaves, S. S. S. (2008). Valores como preditores do bem-estar (Dissertação de mestrado não publicada).Universidade Federal da Paraíba. Brasil.

Esteves, M. L., Jacobs, F., \& Ruiz Fernández, M. I. (2009). Gestão de stress e Reiki: Nova abordagem psicoterapêutica. INFAD: Revista de Psicologia, 3(1), 327-336. Acedido em 23 de Dezembro de 2012 http://infad.eu/RevistaINFAD/2009/n1/volumen3/INFAD_010321_32 7-336.pdf

Farber, B. (1991). Crisis in education: Stress and burnout in the American teacher. San Francisco: Jossey-Bass.

Fore, C., Martin, C., \& Bender, W. N., (2012). Teacher burnout in special education: The causes and the recommended solutions. High School Journal, 86(1), 36-39.

Gasparini, S. M., Barreto, S. M., \& Assunção, A. A. (2006). Prevalência de transtornos mentais comuns em professores da rede municipal de Belo Horizonte, Minas Gerais, Brasil. Cadernos de Saúde Pública, 22(12), 2679-2691.

Gomes, A. P. R., \& Quintão, S. R. (2011). Burnout, satisfação com a vida, depressão e carga horária em professores. Análise Psicológica, 29(2), 335-344. Acedido em http://www.scielo.gpeari.mctes.pt/pdf/aps/v29n2/v29n2a10.pdf

Gouveia, C. J. B. (2010). Burnout, ansiedade e depressão nos professores (Dissertação de mestrado). Acedido em http://repositorio.ul.pt/bitstream/10451/2742/3/ulfp037556_tm_tese.pdf

Küçüksüleymanoğlu, R. (2011). Burnout syndrome levels of teachers in special education in Turkey. International Journal of Special Education, 26(1), 53-63. Acedido em http://eric.ed.gov/?id=EJ921186 
Miranda, M. I. (2008). Estágio supervisionado e prática de ensino: Desafios e possibilidades. Belo Horizonte: Junqueira e Marin.

Moreno-Jiménez, B., Hernández, E. G., \& Gutiérrez, J. L. G. (2000). La evaluación del estrés y el burnout del profesorado: El CBP-R. Revista de Psicología del Trabajo y de las Organizaciones, 16, 1, 331-349.

Mota, M. (2010). Crenças de eficácia individual e coletiva dos professores: Estudo num estabelecimento de ensino particular $e$ cooperativo do Norte de Portugal (Dissertação de mestrado, Universidade Fernando Pessoa). Acedido em http://bdigital.ufp.pt/bitstream/10284/1557/1/DM-MariaMota.pdf

Nauege, M. (2011). A liderança pedagógica e autoeficácia dos professores do ensino superior (Dissertação de mestrado, Universidade Nova de Lisboa). Acedido em http://run.unl.pt/handle/10362/5753

Naujorks, M. I. (2008). Stress e inclusão: Indicadores de stress em professores frente a inclusão de alunos com necessidades educacionais especiais. Cadernos de Educação Especial, 20, 117-125. Acedido em http://coralx.ufsm.br/revce/ceesp/2002/02/a9.htm

Nóvoa, A. (2002). Formação de professores e trabalho pedagógico. Lisboa: Educa.

Pais-Ribeiro, J. L. (1995). Reconstrução de uma escala de locus-decontrolo de saúde. Psiquiatria Clínica, 15(4), 207-214.

Polónio, D. M. M. (1997). Epistemologia das ciências da educação: A emergência de uma ciência da educação e o papel fundamental da filosofia da educação. Millenium, 6. Acedido em http://www.ipv.pt/millenium/pce6_dmp.htm

Portugal, Instituto Nacional de Estatística. (2009). Estatísticas demográficas 2008. Lisboa: INE. Acedido em $\mathrm{http} / / / \mathrm{www}$.ine.pt/xportal/xmain?xpid=INE\&xpgid=ine_publicacoes \& PUBLICACOESpub_boui $=71446801 \&$ PUBLICACOESmodo $=2$

Pyhalto, K., Pietarinen, J., Salmela-Aro, K. (2011). Teacher-workingenvironment fit as a framework for burnout experienced by finnish teachers. Teaching and Teacher Education: An International Journal of Research and Studies, 27(7), 1101-1110. DOI: 10.1016/j.tate.2011.05.006.

Rita, J. S., Patrão, I. A. M., \& Sampaio, D. (2010, Fevereiro). Burnout, stress profissional e ajustamento emocional em professores portugueses do ensino básico e secundário. In C. Nogueira (Ed.), Actas do VII Simpósio Nacional de Investigação em Psicologia (pp. 1151-1161). Braga: Universidade do Minho. Acedido em 
http://repositorio.ispa.pt/bitstream/10400.12/1531/1/SNIP\%202010\%2 01151-\%201161.pdf

Sampaio, E. S. (2009). Síndrome de Burnout em professores e alunos do Programa de Mestrado Ensino de Ciências na Amazónia: Uma contribuição para a formação de professores (Dissertação de mestrado, Universidade do Estado do Amazonas). Acedido em http://www.pos.uea.edu.br/data/area/titulado/download/14-7.pdf 